\title{
A rare recurrence of bilateral breast cancer in the esophagus coincidentally associated with primary gastric cancer: a case report
}

\author{
Shinichiro Kashiwagi", Naoyoshi Onoda, Yuka Asano, Satoru Noda, Hidemi Kawajiri, Tsutomu Takashima, \\ Tetsuro Ishikawa and Kosei Hirakawa
}

\begin{abstract}
Introduction: Cases of esophageal metastasis of breast cancer are extremely rare. We present the case of a patient who developed recurrence as esophageal metastasis following treatment of bilateral breast cancer. Early-stage gastric cancer was also found coincidentally.

Case presentation: An 86-year-old Japanese female patient with a history of bilateral breast cancer was found to have a gastric mass on a medical examination. At 72 years of age, she had undergone a total mastectomy with level II axillary lymph node dissection (pT3NOMO stage II). Left breast cancer was found at the age of 79. A total mastectomy was performed with level II axillary lymph node dissection (pT1NOMO stage I). At the time of her current admission, our patient complained of dysphagia. A repeat gastrofiberscopy revealed a submucosal lesion in her middle esophagus, located $27 \mathrm{~cm}$ distal to her incisors, as well as a known type I tumor of the gastric cardia. Computed tomography showed a mass lesion in her middle esophagus that had grown extraluminally and infiltrated the tracheal bifurcation and her left primary bronchus. A boring biopsy of the esophageal lesion was performed under ultrasonic monitoring, and a pathological diagnosis of poorly differentiated adenocarcinoma of the esophagus was obtained. The biopsy of the cardiac lesion revealed moderately differentiated adenocarcinoma of the stomach. The expression status of her hormone receptors indicated that the esophageal lesion reflected metastatic recurrence of her breast cancer with coincidental primary gastric cancer (CT1NOMO stage IA).
\end{abstract}

Conclusions: Esophageal metastasis of breast cancer is extremely rare. An individualized treatment plan combining multimodal approaches should therefore be devised according to the patient's status.

\section{Introduction}

Distant metastasis from primary breast cancer often occurs in the bones, lungs and liver. There are a few reports of metastasis to the gastrointestinal trunk [1], but cases of esophageal metastasis are extremely rare $[2,3]$. We present the case of a patient who developed recurrence as esophageal metastasis following treatment of bilateral breast cancer. Early-stage gastric cancer was also found coincidentally. To the best of our knowledge, there have been no previous reports of such a case. We present this case with a discussion of the diagnosis and treatment strategies.

\footnotetext{
*Correspondence: spqv9ke9@view.ocn.ne.jp

Department of Surgical Oncology, Osaka City University Graduate School of Medicine, 1-4-3 Asahi-machi, Abeno-ku, Osaka, Japan
}

\section{Case presentation}

An 86-year-old Japanese female patient with a history of bilateral breast cancer was found to have a gastric mass on a medical examination. She was referred to our hospital for a workup and treatment. She had previously undergone surgery for right breast cancer at 72 years of age and subsequently underwent total mastectomy with level II axillary lymph node dissection. The pathological examination at that time revealed invasive ductal carcinoma with positive lymphovascular invasion (pT3NOM0 stage II). The tumor was positive for both estrogen receptor (ER) and progesterone receptor (PR), and did not overexpress human epidermal growth factor receptor 2 (HER2). A total of 50Gy of external beam irradiation therapy was administered to her residual mammary gland, followed by endocrine therapy with $20 \mathrm{mg}$ of daily

\section{Biomed Central}

(c) 2014 Kashiwagi et al.; licensee BioMed Central Ltd. This is an Open Access article distributed under the terms of the Creative Commons Attribution License (http://creativecommons.org/licenses/by/2.0), which permits unrestricted use, distribution, and reproduction in any medium, provided the original work is properly credited. 

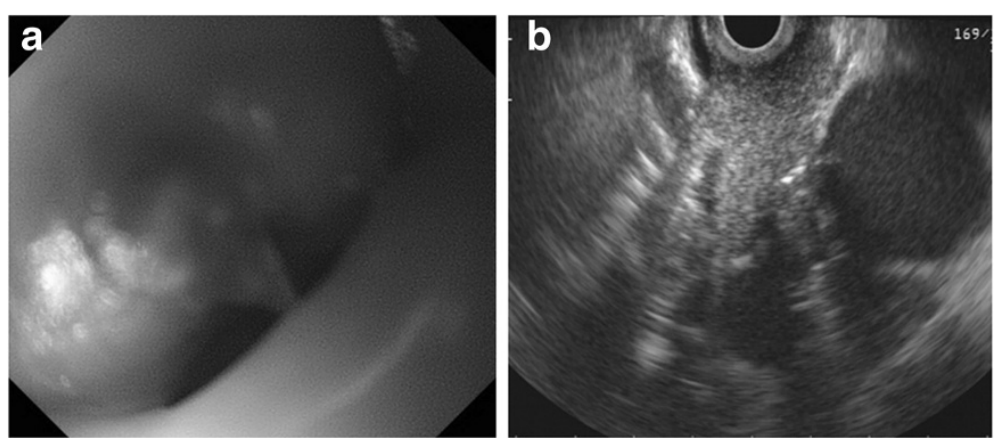

Figure 1 Gastrofiberscopy and fine-needle aspiration cytology. (a) Gastrofiberscopy revealed a submucosal lesion of the middle esophagus. (b) Fine-needle aspiration cytology and a boring biopsy of the esophageal lesion were obtained under ultrasonic monitoring.

tamoxifen administration for five years. She was found to have left breast cancer at the age of 79 years. A total mastectomy was performed with level II axillary lymph node dissection, and invasive ductal carcinoma with positive lymphovascular invasion (pT1N0M0 Stage I) was diagnosed. As before, the tumor was positive for ER and PR with no HER2 overexpression. She received extended adjuvant endocrine therapy of $1 \mathrm{mg}$ per day of anastrozole for five years.

On her current admission, our patient complained of dysphagia. Repeat gastrofiberscopy revealed a submucosal lesion in her middle esophagus located $27 \mathrm{~cm}$ distal to her incisors (Figure 1a), as well as the known type I tumor (semipedunculated type) of her gastric cardia (Figure 2). Biochemistry and blood testing did not reveal any abnormal values. Her level of squamous cell carcinoma antigen was elevated $(5.4 \mathrm{ng} / \mathrm{mL})$; however, the values of the other markers (carcinoembryonic antigen, carbohydrate antigen 15-3, National Cancer Center-ST 439, cytokeratin 19 fragment) were within the normal ranges. Mediastinal computed tomography showed a mass lesion in her middle esophagus that had grown extraluminally and infiltrated the tracheal bifurcation and her left primary bronchus (Figure 3). There was no hepatic or pulmonary metastasis. Fine-needle aspiration cytology and a boring biopsy of the esophageal lesion were performed under ultrasonic monitoring (Figure 1b), and a pathological diagnosis of poorly differentiated adenocarcinoma of the esophagus was obtained with positive ER staining on immunohistochemistry (Figure 4a). A biopsy of the cardiac lesion revealed moderately differentiated adenocarcinoma of the stomach (Figure $4 \mathrm{~b}$ ). Neither hormone receptors nor HER2 were expressed in the gastric lesion. The expression status of the hormone receptors indicated that the esophageal lesion reflected metastatic recurrence of her breast cancer with coincidental primary gastric cancer (cT1N0M0 stage IA).

Although our patient's dysphagia progressed, neither intensive chemotherapy nor highly invasive surgical therapy were considered to be indicated due to her general condition and age. The esophageal lesion was treated with $2 \mathrm{~Gy}$ per day of external beam irradiation therapy for 30 days (for a total of 60Gy). It remarkably reduced in size after radiotherapy (Figure 5a), allowing oral inoculation. The cardiac tumor exhibited no remarkable changes (Figure 5b). Endoscopic submucosal dissection was considered for the gastric tumor. Unfortunately, endoscopic ultrasonography (EUS) demonstrated that the tumor had invaded her submucosal layer and it was judged to be inoperable due to the risk of bleeding and

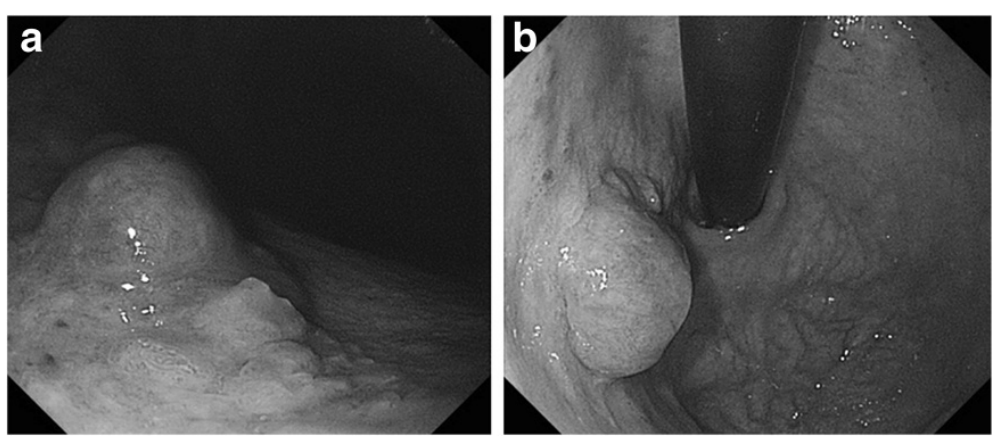

Figure 2 Gastrofiberscopy revealed a type I tumor (semipedunculated type) of the gastric cardia (a, b). 

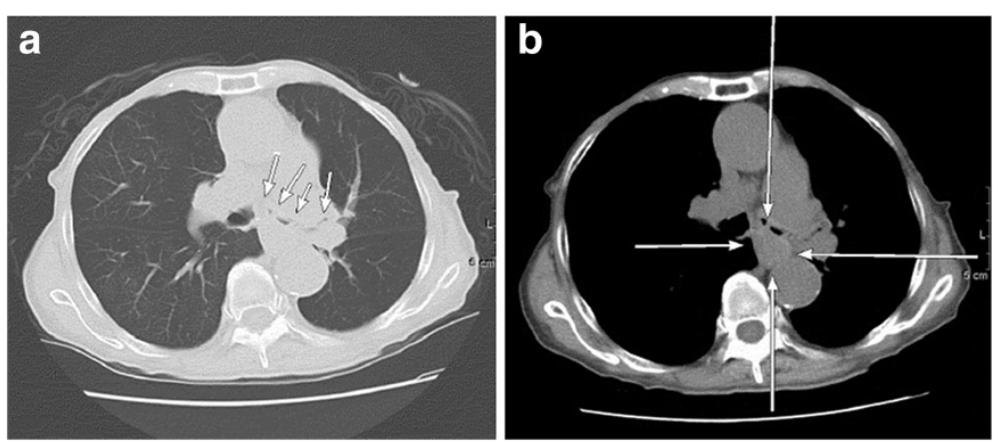

Figure 3 Mediastinal computed tomography showed a mass lesion on the middle esophagus that had grown extraluminally and had infiltrated the tracheal bifurcation and the left primary bronchus $(a, b)$.

perforation. The administration of chemotherapy and endocrine therapy for her breast cancer was prioritized because the esophageal lesion of the breast cancer was much more advanced and critical for our patient's status than the gastric cancer. She received metronomic medication with daily oral administration of tegafur-uracil (400mg per kilogram body weight), cyclophosphamide $(100 \mathrm{mg} /$ day) and medroxyprogesterone acetate $(800 \mathrm{mg} /$ day) based on her age and therapeutic history, as well as the biological subtype of the tumor and presence of the non-treated gastric cancer. She has since maintained a good performance status on outpatient treatment with chemo-endocrine therapy, and no disease progression had been noted to date, six months after the radiation therapy.

\section{Discussion}

Gastrointestinal metastasis of breast cancer is rare, with an incidence of $4.3 \%$ to $14.4 \%$ [1]. Although gastric metastasis of breast cancer is sometimes reported [1], metastasis to the esophagus occurs extremely rarely. According to Borst and Ingold, who observed a total of 2,246 patients with breast cancer over 18 years, the incidence of esophageal metastasis was only $0.4 \%$ [4]. There are very few case reports of such metastasis [5-19] (Table 1); based on a search of PubMed, only 20 cases have been reported. We found no reports describing a case of gastric metastasis of breast cancer accompanied by gastric cancer or occurring after treatment for bilateral breast cancer.

Esophageal metastasis of breast cancer is usually detected at an average of approximately seven years (range 3.5 to 24 years) after breast resection [20]. Symptoms include dysphagia, hoarseness and weight loss; however, such symptoms are observed only in approximately $30 \%$ of patients [21]. Esophageal metastasis of breast cancer causes compression or stenosis of the esophagus due to metastasis within the esophageal wall or to the mediastinal lymph nodes near the esophagus. Therefore, the mucosal surface is usually not involved. These features were also found in our patient. Esophagography and endoscopy are the diagnostic tools. The findings of these tests are characterized by regular stenosis of the esophagus as well as a lack of abnormalities of the mucosal surface. Biopsies often do not reveal malignant findings. Therefore, submucosal boring biopsies and aspiration cytology are recommended for biopsy-based diagnosis. Our patient was given a diagnosis based on successful EUS-guided fine-needle aspiration cytology and a boring biopsy, an alternative method for obtaining submucosal tumor tissues. Most esophageal metastases originating
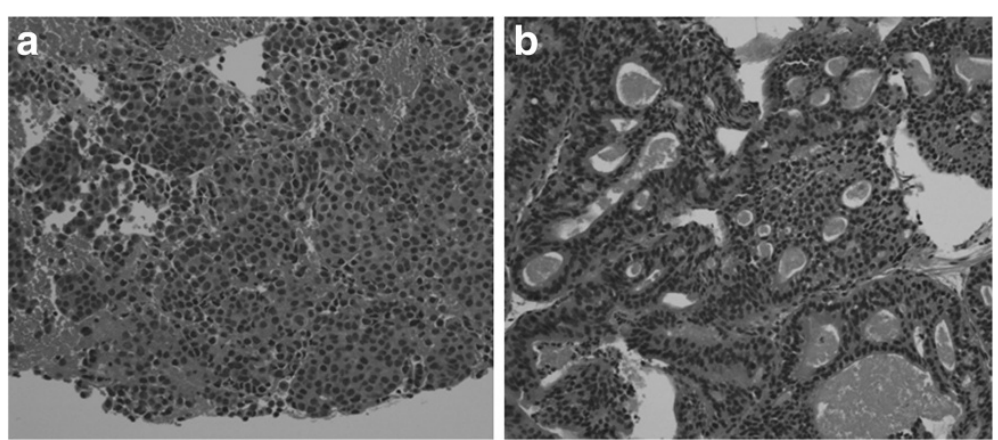

Figure 4 Histological findings of the biopsy. (a) Poorly differentiated adenocarcinoma of the esophagus. (b) Adenocarcinoma of the stomach. 

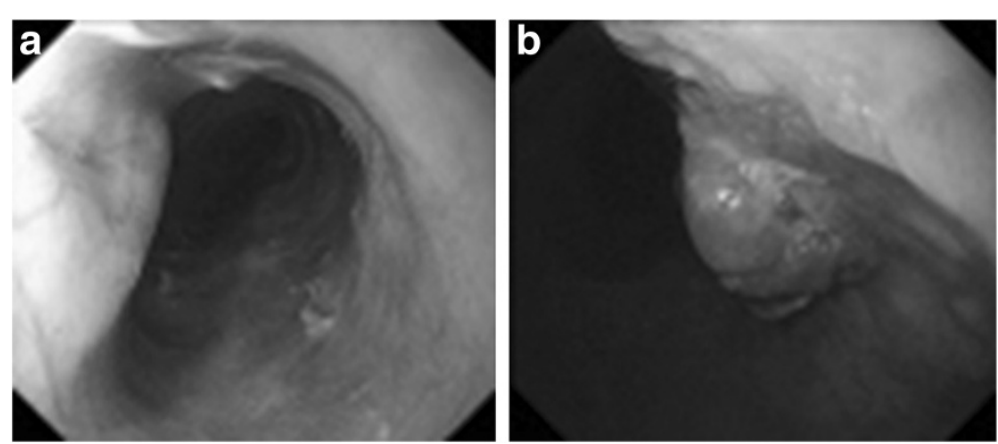

Figure 5 Gastrofiberscopy after radiotherapy. (a) The esophageal tumor was remarkably reduced in size. (b) The cardiac tumor showed no remarkable change.

from breast cancer exhibit submucosal lesions [5-19]. Therefore, patients presenting with dysphagia should not be assumed to have benign stricture involvement even if a mucosal biopsy does not demonstrate malignancy. As a result, the indications for EUS are useful in such situations, as observed in our case.
The prognosis of metastatic breast cancer to the esophagus is poor, and it is reasonable to regard the disease as a highly advanced breast cancer $[2,20]$. Therefore, the therapeutic strategy should always be individually planned. According to a literature review, surgical therapy has been performed in nine patients, four of whom survived for

Table 1 Reported cases of esophageal metastasis from breast cancer

\begin{tabular}{|c|c|c|c|c|c|c|}
\hline Author & Year & Age & Location & Latent interval (years) & Treatment & Survival \\
\hline Haim et al. [5] & 1989 & 50 & Mt & 12 & $\mathrm{D} / \mathrm{HT} / \mathrm{RT}$ & 1 year/AOD \\
\hline Issacs et al. [6] & 1989 & 60 & $M t, L t$ & 5 & $\mathrm{D} / \mathrm{HT}$ & $-1-$ \\
\hline Shimada et al. [7] & 1989 & 55 & $\mathrm{Lt}$ & 9 & $\mathrm{HT} / \mathrm{OP}$ & 5 years/AOD \\
\hline Herrera [8] & 1992 & 78 & EGJ & 21 & $\mathrm{HT} / \mathrm{OP}$ & Postop/DOD \\
\hline Labenz et al. [9] & 1993 & 61 & $\mathrm{Mt}$ & - & S & 0.4 years/AOD \\
\hline Hastier et al. [10] & 1994 & 42 & $\mathrm{Lt}$ & 9 & & $-/ D O D$ \\
\hline \multirow[t]{4}{*}{ Varanasi et al. [11] } & 1995 & 63 & Mt & 8 & $\mathrm{D} / \mathrm{OP}$ & $-/-$ \\
\hline & & 64 & Mt & 22 & D/OP/RT & Postop/DOD \\
\hline & & 78 & Mt & 8 & $\mathrm{D} / \mathrm{OP}$ & Postop/DOD \\
\hline & & 67 & $M t, L t$ & 22 & $\mathrm{D} / \mathrm{HT} / \mathrm{RT}$ & 4 years/DOD \\
\hline Mizobuchi et al. [12] & 1997 & 56 & $L t$ & 7 & $\mathrm{CT} / \mathrm{HT} / \mathrm{OP}$ & 4 years/DOD \\
\hline Fujii et al. [13] & 1997 & 68 & Mt & 15 & $\mathrm{HT} / \mathrm{OP}$ & 1 year/AOD \\
\hline Wu et al. [14] & 1998 & 83 & $\mathrm{Mt}$ & 13 & $\mathrm{D} / \mathrm{HT}$ & $-/-$ \\
\hline \multirow[t]{4}{*}{ Simchuk and Low [2] } & 2001 & 73 & $\mathrm{Lt}$ & 9 & $\mathrm{D}$ & 1 year/DOD \\
\hline & & 41 & Mt & 4 & $C T / D$ & 0.1 years/DOD \\
\hline & & 77 & Mt & 3.5 & $D$ & 1.5 years/AOD \\
\hline & & 74 & $\mathrm{Mt}$ & 11 & $\mathrm{D} / \mathrm{S}$ & 0.4 years/DOD \\
\hline Erman et al. [15] & 2002 & 55 & $\mathrm{Mt}$ & 11 & $\mathrm{CT} / \mathrm{HT} / \mathrm{RT}$ & 3 years/AOD \\
\hline Sunada et al. [16] & 2005 & 68 & Mt & 24 & $\mathrm{D} / \mathrm{HT}$ & 0.7 years/AOD \\
\hline \multirow[t]{2}{*}{ Koike et al. [17] } & 2005 & 72 & $\mathrm{Mt}$ & 23 & $\mathrm{OP}$ & 1 year/AOD \\
\hline & & 52 & $\mathrm{Lt}$ & 10 & $\mathrm{D} / \mathrm{HT} / \mathrm{S}$ & $-/-$ \\
\hline Anaya et al. [18] & 2006 & 67 & EGJ & 19 & $\mathrm{HT} / \mathrm{OP}$ & 0.5 years/AOD \\
\hline Wada et al. [19] & 2009 & 70 & $\mathrm{Mt}$ & 16 & $\mathrm{HT} / \mathrm{RT}$ & 2.5 years/AOD \\
\hline Present case & 2011 & 86 & Mt & 7 & HT/RT & 0.5 years $/ A O D$ \\
\hline
\end{tabular}

AOD, alive of disease; $C T$, chemotherapy; D, dilatation; DOD, dead of disease; EGJ, esophagogastric junction; $\mathrm{HT}$, hormonal therapy; Lt, lower thoracic esophagus; $\mathrm{Mt}$, middle thoracic esophagus; $\mathrm{OP}$, operation; RT, radiation therapy; S, stenting. 
more than one year $[7,8,11-13,17,18]$. This result justifies the use of surgical treatment when deemed possible. By contrast, three patients died postoperatively, suggesting the highly invasive nature of surgical therapy when adapted to esophageal lesions [22]. The remaining patients were treated with dilatation, stenting and/or radiation in 13, three and six cases, respectively [5-19]. Only shortterm follow-up results are available for patients who underwent dilatation and stenting (9). Radiation was administered in six cases $[5,11,15,19]$, with a relatively good prognosis of more than one year reported for every patient. All five patients who survived for more than two years received hormone therapy in combination with local treatment with either surgery or radiation. These results indicate that patients exhibiting a response to hormonal therapy, as in our case, may be expected to demonstrate a more favorable prognosis than patients with hormone receptor-negatives tumors. According to our review, as many as 13 of 24 patients with metastatic breast cancer to the esophagus showed positive results for ER and/or PR [5-8,11,17-19]. Therefore, it is thought that active treatment should be provided based on the intrinsic subtype. It is important to administer appropriate multimodal therapy with topical treatment for esophageal lesions (for example, radiotherapy, esophageal bougienage and esophagectomy) $[7,20]$ and systemic treatment for distant metastasis (for example, chemotherapy and endocrine therapy).

The administration of individualized treatment according to the intrinsic subtype is recommended in patients with breast cancer. Endocrine therapy was selected in our case because our patient's breast cancer was classified as luminal A type (ER-positive, HER2-negative, Ki67 $<14 \%$ ). Toremifene, an aromatase inhibitor, was chosen for endocrine therapy because tamoxifen had been used for five years for the right breast cancer that developed at 72 years of age, and anastrozole for the same duration for the left breast cancer, possibly the lesion responsible for the present metastasis, that developed at 79 years of age. The primary tumors of both her breasts and the metastatic lesion demonstrated the same biological nature (ER-positive and HER2-negative). However, untreated early gastric cancer was also coincidentally found in our patient. Therefore, combination therapy was administered with tegafur-uracil, cyclophosphamide and medroxyprogesterone acetate. This combination therapy is reported to be useful for elderly patients [23].

\section{Conclusions}

Esophageal metastasis of breast cancer is extremely rare. An individualized treatment plan combining multimodal approaches should therefore be devised according to the patient's status.

\section{Consent}

Written informed consent was obtained from the patient for publication of this case report and accompanying images. A copy of the written consent is available for review by the Editor-in-Chief of this journal.

\section{Abbreviations \\ ER: estrogen receptor; HER2: human epidermal growth factor receptor 2; PR: progesterone receptor.}

\section{Competing interests}

The authors declare that they have no competing interests.

\section{Authors' contributions}

SK, HK and TT performed clinical work. SK, YA, SN, NO, TI and KH carried out laboratory work. All authors contributed to writing the article. All authors read and approved the final manuscript.

\section{Acknowledgements}

We thank Soichiro Hiramatsu (Osaka City University Graduate School of Medicine) for helpful advice.

Received: 25 June 2013 Accepted: 23 December 2013 Published: 18 February 2014

\section{References}

1. Davis HL, Murray RK, Korbiz BC: Breast carcinoma metastatic to the stomach. Am J Dig Dis New Ser 1968, 13:868-873.

2. Simchuk EJ, Low DE: Direct esophageal metastasis from a distant primary tumor is a subclinical process: a review of six cases. Dis Esophagus 2001, 14:247-250.

3. Kamby C, Vejborg I, Kristensen B, Olsen LO, Mouridsen HT: Metastatic patterns in recurrent breast cancer: special reference to intrathoracic recurrences. Cancer 1988, 62:2226-2233.

4. Borst MJ, Ingold JA: Metastatic patterns of invasive lobular versus invasive ductal carcinoma of the breast. Surgery 1993, 114:637-641.

5. Haim N, Krugliak P, Cohen Y, Schwartzman Z, Benharroch D: Esophageal metastasis from breast carcinoma associated with pseudoepitheliomatous hyperplasia: an unusual endoscopic diagnosis. J Surg Oncol 1989, 41:278-281.

6. Isaacs P, MacGillivray N, Springett P: Late recurrence of breast cancer presenting with esophageal dysmotility. J Clin Gastroenterol 1989, 11:588-590.

7. Shimada Y, Imamura M, Tobe T: Successful esophagectomy for metastatic carcinoma of the esophagus from breast cancer: a case report. Jpn J Surg 1989, 19:82-85.

8. Herrera JL: Benign and metastatic tumors of the esophagus. Gastroenterol Clin North Am 1991, 20:775-789.

9. Labenz J, Madeya S, Boerch G: Post-mastectomy dysphagia: successful treatment with an esophageal self-expanding metallic stent. Gastrointest Endosc 1993, 39:599.

10. Hastier P, Francois E, Delmont JP, Harris AG, Barthel HR, Namer M: Esophageal metastasis from breast cancer detected by hematemesis. Am J Gastroenterol 1994, 89:289-290.

11. Varanasi RV, Saltzman JR, Krims P, Crimaldi A, Colby J: Breast carcinoma metastatic to the esophagus: clinicopathological and management features of four cases, and literature review. Am J Gasteroenterol 1995, 90:1945-1499

12. Mizobuchi S, Tachimori Y, Kato H, Watanabe H, Nakanishi Y, Ochiai A: Metastatic esophageal tumors from distant primary lesions: report of three esophagectomies and study of 1,835 autopsy cases. Jpn J Clin Oncol 1997, 27:410-414.

13. Fujii $K$, Nakanishi $Y$, Ochiai A, Tsuda H, Yamaguchi H, Tachimori Y, Kato H, Watanabe H, Shimoda T: Solitary esophageal metastasis of breast cancer with 15 year' latency: a case report and review of the literature. Pathol Int 1997, 47:614-617.

14. Wu CM, Hruban RH, Fishman EK: Breast carcinoma metastatic to the esophagus. Clin Imaging 1998, 22:343-345.

15. Erman M, Karaoğlu A, Oksüzoğlu B, Aydingöz U, Ayhan A, Güler N: Solitary esophageal metastasis of breast cancer after 11 years. Med Oncol 2002, 19:171-175 
16. Sunada F, Yamamoto H, Kita H, Hanatsuka K, Ajibe H, Masuda M, Hirasawa T, Osawa H, Sato K, Hozumi Y, Sugano K: A case of esophageal stricture due to metastatic breast cancer diagnosed by endoscopic mucosal resection. Jpn J Clin Oncol 2005, 35:483-486.

17. Koike M, Akiyama S, Kodera Y, Nakao A: Breast carcinoma metastasis to the esophagus: report of two cases. Hepatogastroenterology 2005, 52:1116-1118.

18. Anaya DA, Yu M, Karmy-Jones R: Esophageal perforation in a patient with metastatic breast cancer to esophagus. Ann Thorac Surg 2006, 81:1136-1138.

19. Wada Y, Harada N, Ohara K, Kawata H, Iwasaki H, Kawamura Y, Gomi T, Ohtoshi M, Nakashima Y: Esophageal metastasis of breast carcinoma. Breast Cancer 2009, 16:151-156.

20. Anderson MF, Harell GS: Secondary esophageal tumors. Am J Roentogenol 1980, 68:149-153.

21. Goldberg Rl, Rams H, Stone B, Barkin JS: Dysphagia as the presenting symptom of recurrent breast carcinoma. Cancer 1987, 60:1085-1088.

22. Orringer MB, Skinner DB: Unusual presentations primary and secondary esophageal malignancies. Ann Thorac Surg 1971, 11:305-314.

23. Ogawa Y, Ishikawa T, Chung SH, Ikeda K, Takashima T, Onoda N, Nakata B, Nishiguchi Y, Hirakawa K: Oral UFT and cyclophosphamide combination chemotherapy for metastatic breast cancer. Anticancer Res 2003, 23:3453-3457.

doi:10.1186/1752-1947-8-58

Cite this article as: Kashiwagi et al:: A rare recurrence of bilateral breast cancer in the esophagus coincidentally associated with primary gastric cancer: a case report. Journal of Medical Case Reports 2014 8:58.

\section{Submit your next manuscript to BioMed Central and take full advantage of:}

- Convenient online submission

- Thorough peer review

- No space constraints or color figure charges

- Immediate publication on acceptance

- Inclusion in PubMed, CAS, Scopus and Google Scholar

- Research which is freely available for redistribution 